\title{
PEMGEMBANGAN MEDIA PEMBELAJARAN PRAKTEK TARI SURAKARTA I BAGI MAHASISWA JURUSAN PENDIDIKAN SENI TARI FAKULTAS BAHASA DAN SENI UNIVERSITAS NEGERI YOGYAKARTA
}

\author{
ABSTRAK \\ Oleh: Herlinah \\ Jurusan Pendidikan Seni Tari, FBS UNY
}

\begin{abstract}
Penelitian ini bertujuan untuk menghasilkan produk media video pembelajaran tari yang bisa digunakan untuk menunjang pembelajaran mata kuliah Tari Surakarta I bagi mahasiswa Jurusan Pendidikan Seni Tari Fakultas Bahasa dan Seni Universitas Negeri Yogyakarta. Kompetensi yang ingin dicapai melalui media pembelajaran ini adalah meningkatnya teknik gerak, wirama, dan penjiwaan mahasiswa.

Pengembangan video pembelajaran tari Surakarta I ini menggunakan model prosedural dengan 8 tahap pokok, yaitu: (1) analisis kebutuhan, (2) perancangan, (3) pengembangan produk awal, (4) uji validasi ahli, (5) uji coba terbatas, (6) revisi 1 (7) uji coba lapangan, dan (8) evaluasi akhir.

Setelah melalui proses pengembangan produk yaitu melalui uji ahli dan uji coba terbatas diperoleh media video pembelajaran tari. Persepsi mahasiswa tentang kemampuan media untuk meningkatkan motivasi belajar dan pemahaman teknik gerak, irama, ekspresi dan penjiwaan tari adalah sebagai berikut: Perolehan skor persepsi mahasiswa tentang kemampuan media dalam meningkatkan motivasi belajar adalah: 4,25; pemahaman teknik gerak 4,8; pemahaman irama 4, 25; pemahaman ekspresi dan penjiwaan 4. Sedangkan dari segi teknis, persepsi mahasiswa tentang kualitas peraga yang dipergunakan adalah 4,05; kualitas gambar 3,65; kualitas suara 3,8; dan kebermaknaan materi 4,35. Rata-rata skor keseluruhan adalah 4,14. Berdasarkan perolehan skor maka dapat disimpulkan bahwa persepsi mahasiswa tentang kemampuan dan kualitas media video tari Gambyong Pareanom secara keseluruhan adalah baik.
\end{abstract}

Kata Kunci: Pengembangan, Media Pembelajaran, Praktek Tari 


\title{
DEVELOPMENT OF LEARNING MEDIA PRACTICE SURAKARTA I DANCE FOR DANCE EDUCATION DEPARTMENT STUDENT OF THE FACULTY OF LANGUAGES AND ARTS, STATE UNIVERSITY YOGYAKARTA
}

\begin{abstract}
This study aims to produce instructional dance video media that can be used to support learning courses Surakarta I Dance for Dance Education student of the Faculty of Languages and Arts, State University of Yogyakarta. Competencies to be achieved through the medium of this study is the increased movement techniques, wirama,and inspiration of students.

Development of instructional dance videos Surakarta I use procedural models with 8 principal stages, namely : ( 1 ) needs analysis, ( 2 ) design, ( 3 ) the initial product development, ( 4 ) validation test expert, ( 5 ) limited testing, ( 6 ) revision 1 ( 7 ) field trials, and (8) the final evaluation.

After going through the process of product development is through expert testing and obtained limited trial dance lesson video media. Student perceptions about the ability of the media to improve learning motivation and understanding of motion technique, rhythm, expression and inspiration of dance are as follows : Acquisition score students' perceptions about the ability of the media in enhancing motivation to learn are : 4.25; understanding of motion technique 4.8; understanding of rhythm 4, 25; understanding of expression and inspiration 4. While from a technical perspective, students' perceptions about the quality of teaching that is used is $4.05 ; 3.65$ image quality; 3.8 sound quality, and meaningfulness of material 4.35. Average overall score was 4.14. Based on the acquisition scores it can be concluded that the students' perceptions about the capabilities and quality of video media dance Gambyong Pareanom overall is good .
\end{abstract}

Keywords: Development, Learning Media, Dance Practice 


\section{A. PENDAHULUAN}

Mata kuliah Tari Surakarta I merupakan mata kuliah yang terdapat di Jurusan Pendidikan Seni Tari Fakultas Bahasa dan Seni Universitas Negeri Yogyakarta. Mata kuliah Tari Surakarta I merupakan materi wajib yang harus ditempuh pada mahasiswa semester 3. Dalam mata kuliah Tari Surakarta I ada dua materi yang harus disampaikan kepada mahasiswa yaitu tari tunggal dan tari berpasangan. Materi tari Tunggal adalah bentuk tari putri yaitu Tari Gambyong Pareanom, sedangkan tari berpasangan adalah adalah bentuk tari putra gagah dan putra halus, yaitu Tari Sancaya Kusumawicitra. Proses pembelajaran Tari Surakarta I yang dilaksanakan pada Program Studi Pendidikan Seni Tari Fakultas Bahasa Seni Universitas Negeri Yogyakarta selama ini menggunakan metode konvensional, atau juga disebut metode imitasi. Metode imitasi tersebut, dosen memberikan contoh gerak kepada mahasiswa kemudian mahasiswa menirukan contoh gerak yang diberikan oleh dosen. Dengan demikian dosen mempunyai peran sentral dalam pembelajaran. Pembelajaran seperti itu, akan membuat mahasiswa pasif kurang berfikir secara kreatif.

Oleh karena itu, maka perlu adanya peningkatan mutu dalam proses pembelajaran. Salah satu upaya untuk meningkatkan mutu pembelajaran tari agar dosen tidak menjadi peran sentral adalah dengan perbaikan proses pembelajaran tari. Untuk itu, Dawud, dkk. (2004:v) menyarankan agar pendekatan pembelajaran yang menempatkan guru sebagai sentral kegiatan belajar mengajar sedikit demi sedikit mulai ditinggalkan. Di sisi lain Sukirno (2008: 2) mengatakan bahwa, pembelajaran perpusat pada mahasiswa akan lebih bermakna jika mahasiswa mengalami apa yang dipelajari, bukan hanya mengetahuinya, dengan konsep seperti itu, hasil pembelajaran diharapkan lebih bermakna bagi mahasiswa. Sejalan dengan hal tersebut, Sukirno (2008:1) mengatakan bahwa berbagai konsep dan wawasan baru tentang proses pembelajaran telah muncul dan berkembang seiring dengan pesatnya perkembangan ilmu pengetahuan dan teknologi. Model pembelajaran merupakan salah satu komponen penting dalam proses belajar mengajar, karena dengan berbagai model dan metode materi dapat tersampaikan. 
Oleh karenannya, seorang dosen harus kreatif melakukan eksperimen-eksperimen dengan menggunakan berbagai model atau dengan media pembelajaran yang sesuai dengan karakteristik materi ajar. Sehubungan dengan hal tersebut, seyogyanya pembelajaran praktek tari dilengkapi dengan media pembelajaran yang memungkinkan mahasiswa bisa belajar secara lebih mandiri dan efisien.

Seperti yang diungkapkan oleh Sardiman (2011: 7) bahwa media video merupakan salah satu media pendidikan yang digunakan dalam proses belajar mengajar agar siswa lebih kreatif dan mandiri. Berdasarkan masalah tersebut, maka peneliti menganggap perlu adanya pengembangan model pembelajaran untuk praktek tari. Salah satu media pembelajaran yang tepat dan sesuai dengan kompetensi serta karakteristik materi tari adalah media video pembelajaran.

\section{B. KAJIAN TEORI}

Pengembangan merupakan proses sistematis dalam mengidentifikasi masalah, mengidentifikasi standar kompetensi dan kompetensi dasar, memilih bahan, menentukan strategi pembelajaran, dan mengevaluasi keefektifan dan efisiensi produk sehingga menghasilkan pembelajaran yang efektif (Sukirno, 2008: 26). Dilain pihak Darmawan (2012 : 12) mengatakan bahwa pengembangan merupakan proses penerjemahan spesifikasi desain ke dalam bentuk fisik kawasan. Dalam kawasan pengembangan terdapat keterkaitan yang kompleks antara teknologi dan teori yang mendorong baik desain pesan maupun strategi pembelajaran.

Media pembelajaran merupakan komponen instruksional yang meliputi pesan, orang, dan peralatan. Secara umum media adalah alat bantu proses belajar mengajar yang dapat menyampaikan pesan, merangsang pikiran, perasaan, dan kemauan peserta didik sehingga dapat mendorong terciptanya proses belajar mengajar pada diri si siswa tersebut. Menurut Seels \& Richey dalam Arsyad (2013: 31) mengatakan bahwa dalam perkembangannya media pembelajaran mengikuti perkembangan teknologi. Dikatakan pula bahwa berdasarkan perkembangan teknologi tersebut, media pembelajaran dapat dikelompokkan ke dalam empat kelompok, yaitu: (1) media hasil teknologi cetak, (2) media hasil 
teknologi audio-visual, (3) media hasil teknologi yang berdasarkan komputer, dan (4) media hasil gabungan teknologi cetak dan komputer (Arsyad, 2013: 31).

Berdasarkan uraian tersebut di atas, maka media pada hakekatnya memungkinkan terjadinya komunikasi dalam penyampaian pesan yang berlangsung antara pengirim kepada penerima. Dalam pembelajaran Tari Surakarta I ada satu media pembelajaran yang diperlukan yaitu: media video pembelajaran Tari khususnya pada Tari Gambyong Pareanom.

Pembelajaran menurut Hamalik (1995: 57) adalah suatu kombinasi yang tersusun meliputi unsur-unsur manusiawi siswa dan guru, material (buku, papan tulis, kapur, dan alat belajar), fasilitas (ruang, kelas dan audio visual), dan proses yang saling mempengaruhi pencapaian tujuan pembelajaran. Untuk itulah pembelajaran yang baik adalah pembelajaran yang berkualitas. Pembelajaran yang berkualitas adalah pembelajaran yang prosesnya baik dan membuahkan hasil yang maksimal. Dalam dunia pendidikan di Indonesia, pembelajaran yang berkualitas dan diidam-idamkan oleh selurah insan pendidikan adalah pendidikan yang aktif, kreatif, efektif, menyenangkan, dan inovatif. Namun demikian, dalam penerapannya diperlukan kreativitas dosen untuk menyesuaikan dengan karakteristik materi dan tujuan perkuliahannya.

Di samping itu, dari segi outcome, pembelajaran tari adalah jenis pembelajaran yang bersifat khas. Mengacu pada teori belajar Gagne (via woolfolk and Nicolich, 1984: 232) berdasarkan outcomenya jenis belajar dibedakan menjadi beberapa kategori, yaitu: (1) belajar kecakapan intelektual, (2) belajar informasi verbal, (3) belajar sikap, (4) belajar keterampilan motorik, dan (5) belajar strategi kognitif. Berdasarkan kategorisasi ini, pembelajaran tari Surakarta termasuk kategori pembelajaran keterampilan motorik. Pada pembelajaran jenis ini ada dua komponen penting yang harus diperhatikan yaitu, yang pertama adalah pengetahuan mengenai teknik, atau prosedur bagaimana melakukan suatu keterampilan, dan kedua adalah seringnya latihan-latihan. Dengan demikian pembelajaran yang baik pada pembelajaran tari Surakarta adalah pembelajaran yang memberikan ruang yang sebesar-besarnya bagi latihan-latihan gerak yang dilandasi pengetahuan dan pemahaman teknik gerak yang benar. Berkaitan 
dengan hal tersebut, dapat disarikan bahwa pembelajaran tari Surakarta I yang berkualitas dapat terwujud apabila dosen mampu memadukan antara karakteristik pembelajaran keterampilan motorik yang memerlukan banyak drill dan pembelajaran inovatif yang memerlukan berbagai sumber belajar dan variasi proses.

Pembelajaran tari dengan media pembelajaran bukanlah menggantikan peran dosen. Media pembelajaran yang dikembangkan hanyalah sebagai alat bantu yang difungsikan untuk meningkatkan efektifitas pembelajaran. Namun demikian, pembelajaran dengan media pembelajaran memerlukan pengelolaan yang sesuai dengan karakteristik media dan pembelajaran inovatif.

\section{METODE PENELITIAN}

Pendekatan penelitian yang dipergunakan dalam studi ini adalah pendekatan penelitian pengembangan (Research and Development). Penelitian pengembangan adalah jenis penelitian yang bertujuan menghasilkan produk inovatif yang pengembangannya sudah melalui prosedur ilmiah dan tervalidasi. Dengan pendekatan penelitian ini diharapkan bisa dihasilkan produk inovatif dalam pembelajaran yang sesuai dengan kebutuhan lapangan. Dalam hal ini, kebutuhan media pembelajaran yang dimaksud adalah video pembelajaran tari Surakarta Ikhususnya pada materi Gambyong Pareanom. untuk mahasiswa program Studi Pendidikan Seni tari Fakultas Bahasa dan Seni Universitas Negeri Yogyakarta.

Subjek penelitian ditentukan berdasarkan analisis kebutuhan dan tahapan penelitian. Secara umum, ada tiga kategori subjek penelitian yang ditentukan dan dipergunakan dalam penelitian ini, yaitu dua orang subjek ahli, yang berfungsi sebagai subjek validasi dan uji coba produk, yaitu Dra. Yuli Sectiorini, M.Hum. dari Jurusan Pendidikan Seni Tari Fakultas Bahasa dan Seni Universitas Negeri Yogyakartasebagai subyek ahli materi dan Drs. Marwanto, M.Hum dari jurusan Pendidikan Seni Tari Fakultas Bahasa dan Seni Universitas Negeri Yogyakarta sebagai subyek ahli media. Keduaadalah 12 orang mahasiswa yang mengambil mata kuliah Tari Surakarta I tahun 2013 untuk validasi produk akhir. 
Penelitian pengembangan ini melalui beberapa tahapan yang secara umum dapat dideskripsikan sebagai berikut:

1. Analisis kebutuhan dan penelusuran konsep

Metode yang dipergunakan adalah pengamatan selama proses pembelajaran dan ujian praktik tari. Dengan cara ini dapat diketahui kelemahan proses dan hasil pembelajaran sehingga bisa dirancang solusi pemecahannya.

2. Perancangan

Perancangan program ini meliputi kegiatan pembuatan disain atau skenario program, penentuan peraga (penari) penentuan kameramen, tempat, dan segala peralatan yang dibutuhkan.

3. Pengembangan produk awal

Pengembangan produk awal ini berupa pengambilan adegan seluruh adegan audio visual, display kostum, display rias, tarian secara utuh.

4. Uji validasi Ahli

Uji validasi ahli adalah suatu kegiatan untuk menyaring masukan mengenai kekurangan-kekurangan program baik dari segi teknis atau kualitas media, maupun kebenaran materi program. Subjek ahli yang dimaksud di sini adalah ahli bidang studi(materi) dan ahli media.

\section{Uji Coba Kelompok Kecil}

Uji coba kelompok kecil dilakukan untuk menjaring masukan-masukan mengenai kesesuaian produk dengan kebutuhan mahasiswa dan kemungkinankemungkinan masukan mengenai kekurangan-kekurangan produk yang harus dibenahi.

6. Revisi I

Setelah masukan-masukan dari subjek ahli dan dari mahasiswa diperoleh, langkah selanjutnya adalah revisi produk tahap I. Dalam penelitian ini, hasil revisi produk tahap I ini dipergunakan untuk dasar pengambilan data kepada kelompok mahasiswa yang lebih besar.

7. Uji coba Kelompok Besar

Uji coba kelompok besar merupakan langkah pengambilan data akhir menggunakan subjek yang sesungguhnya. Uji coba kelompok besar dilakukan 
terhadap 12 mahasiswa yang mengambil mata kuliah Tari Surakarta I pada semester gasal tahun 2013.

8. Evaluasi Akhir

Evaluasi akhir dimaksudkan untuk menentukan kualitas produk media pembelajaran berdasarkan respon mahasiswa mengenai efektivitas media dalam meningkatkan pemahaman tentang wiraga, wirama, dan wirasa(penjiwaan),serta motivasi belajar mahasiswa.

Teknik pengumpulan data yang dipergunakan dalam uji validasi dan evaluasi akhir adalah dengan angket. Instrumen utama yang dipergunakan untuk penggalian data berupa pertanyaan-pertanyaan terstruktur dan essay bebas. Pada bagian essay bebas diharapkan subjek penelitian memberikan masukan-masukan mengenai kesempurnaan produk.

Teknik analisis data penelitian ini ada dua macam. Yang pertama adalah teknik kualitatif dipergunakan untuk mensintesakan berbagai masukan yang diperoleh dari subjek penelitian. Yang kedua adalah menggunakan statistik deskriptif untuk mengevaluasi data akhir.

\section{HASIL DAN PEMBAHASAN}

\section{Proses Pengembangan Produk Media Pembelajaran}

\section{a. Model dan Prosedur Pengembangan}

Pengembangan media video pembelajaran tari Surakarta I ini menggunakan model prosedural dengan 8 tahap pokok, yaitu: (1) analisis kebutuhan dan penelusuran konsep, (2) perancangan (disain), (3) Pengembangan produk awal, (4) uji validasi ahli, (5) uji coba terbatas, (6) revisi I, (7) uji coba lapangan, dan (8) evaluasi akhir.

\section{b. Proses Pengembangan Produk Media Pembelajaran}

Prosedur proses pengembangan produk media pembelajaran video ini dapat dideskripsikan sebagai berikut.

\section{1). Analisis Kebutuhan}


Dengan menggunakan metode pengamatan selama proses pembelajaran tari Gambyong Pareanom dapat diidentifikasi beberapa kelemahan proses dan hasil pembelajaran tari Surakarta sebagai berikut:

a. Dilihat dari segi proses pembelajaran, mahasiswa masih sangat tergantung kepada dosen

b. Dilihat dari hasil pembelajaran, mahasiswa masih kelihatan lemah dalam memahami teknik gerak wiraga, wirama, danwirasa (penjiwaan).

\section{2). Perancangan}

Perancangan program meliputi kegiatan penentuan peraga, kameramen, tempat, dan segala peralatan yang dibutuhkan serta pembuatan disain atau skenario program. Adapun indikator aspek-aspek Tari Gambyong Pareanom adalah sebagai berikut:

\section{a) Kebaran: Ulap-ulap kiri}

Pada ragam gerak ulap-ulap ini diawali dengan srisig terlebih dahulu, kemudian maju kaki kanan, kiri, kanan (kaki jejer) dengan kedua tangan kebyoksampur, kebyak kemudian seblak kedua sampur. Ragam gerak ulap-ulap ini dilakukan dengan irama lombo-ngracik.

\section{b). Kebaran: Mudra}

Gerak ini dilakukan dengan tangan kiri ngolong sampur di depan cethik kiri, tangan kanan nekuk kemudian menthang, gerak ini dilakukan dengan irama lombo-ngracik.

\section{c). Batangan}

Gerak ini dilakukan dengan mancat kaki kiri, dan menthang (ngembat) tangan kanan, tangan kiri nekuk trap cethik kiri, tolehan ke kiri kemudian ke kanan. Gerak ini dilakukan lima kali dengan posisi kaki dan tangan bergantian, dengan irama kendang ciblonan.

\section{d). Tatapan}

Gerak ini dilakukan, tangan kiri ulap-ulap tangan kanan trap cethik kanan, disertai ogek lambung. Gerak ini dilakukan berulang-ulang 8 X4 hitungan dengan posisi tangan bergantian kanan dan kiri. 


\section{e). Pilesan}

Gerak pilesan dilakukan dengan sikap tangan kiri sampir sampur di tangan kiri posisi tangan ukel mlumah dan ukel utuh, tangan kanan ditarik nekuk kemudian seblak sampur, disertai tolehan ke kiri dan ke kanan.

\section{f). Tumpang Tali}

Gerak ini dilakukan dengan posisi awal kaki kanan jinjit di belakang, tangan kanan trap cethik kanan ukel mlumah kemudian ukel tanggung, tangan kiri ngembat, tolehan ke kiri. Gerak ini dilakukan dengan maju ke depan kemudian belok kiri disertai kengser.

\section{g). Lumaksana Lembehan}

Gerak ini dilakukan dengan lumaksana ke depan kemudian belok kiri, tangan kanan trap cethik nggegem sampur, tangan kiri miwir sampur lembehan. Diteruskan dengan lembehan sampur tangan kanan, tangan kiri rimong sampur dengan posisi maju dan ke samping kanan.

\section{h). Kawilan}

Gerak ini dumulai dari seblak kedua sampur, kaki jejer, tangan kanan menthang, tanga kiri nekuk trap cethik, disertai kepala. Dilakukan bergantian dengan tangan kiri dengan posisi yang sama.

\section{i). Gajah Ngoling}

Gerak ini dilakukan dengan kaki maju, kedua tangan ngolong sampur dengan gerakan ukel mlumah dan ukel tanggung di depan dada bergantian, kemudian diteruskan dengan tawing kiri, tangan kanan trap cethik kanan posisi putar sampai menghadap ke depan.

\section{j). Menthogan}

Gerak ini dilakukan maju kemudian belok kiri, langkah kesamping kanan, dengan tangan kiri menthang miwir sampur, tangan kanan ukel utuh di depan cethik kanan. Dilakukan 2 X 8 diteruskan dengan srisig kiri.

\section{k). Kesedan}

Kesedan dilakukan dengan kesed ke kanan dengan irama lombo, kemudian berhenti dengan irama rangkep, tangan kiri menthang sampur disampirkan di lengan, tangan kanan ukel utuh di depan cethik kanan, dilakukan 4 X 8 hitungan. 


\section{1). Mande Sampur}

Gerak ini dilakukan dengan jalan kesamping kanan kemudian kengser, tangan kiri ngolong sampur dengan posisi tangan mlumah, tangan kanan ngolong sampur di depan cethik kanan, tolehan ke kiri disertai kepala, dilakukan $3 \times 8$ dengan penghubung kipat srisig.

\section{m). Entragan}

Gerak ini dilakukan dengan kedua tangan di depan pusar, tangan kiri ditarik ke atas, tangan kanan ke bawah, dengan sikap kaki jejer mendak mumbul/ngentrak, tolehan mengikuti gerakan tangan. Dilakukan bergantian ngracik-lombo, trap karna kanan ogek lambung $1 \mathrm{X}$, seblak kedua sampur.

\section{n). Menthogan}

Gerak ini dilakukan pada hitungan 1-8 pertama rimong sampur maju, 1-8 kedua tawing tangan kiri tangan kanan malangkerik jalan ke samping kanan dengan posisii perputar, 1-8 ketiga menthang sampur tangan kanan tangan kiri nekuk trap cethik jalan ke samping kiri hadap depan, 1-4 berikutnya menthang samput tangan kiri tangan kanan nekuk trap cethik kanan jalan ke samping kanan hadap depan dilanjutkan srisig kanan. 
Skenario pembuatan media penelitian dibuat secara sederhana, hal ini dikarenakan peneliti kurang menguasai istilah-istilah teknis dalam media video. Secara lengkap, skenario pembuatan media adalah sebagai berikut:

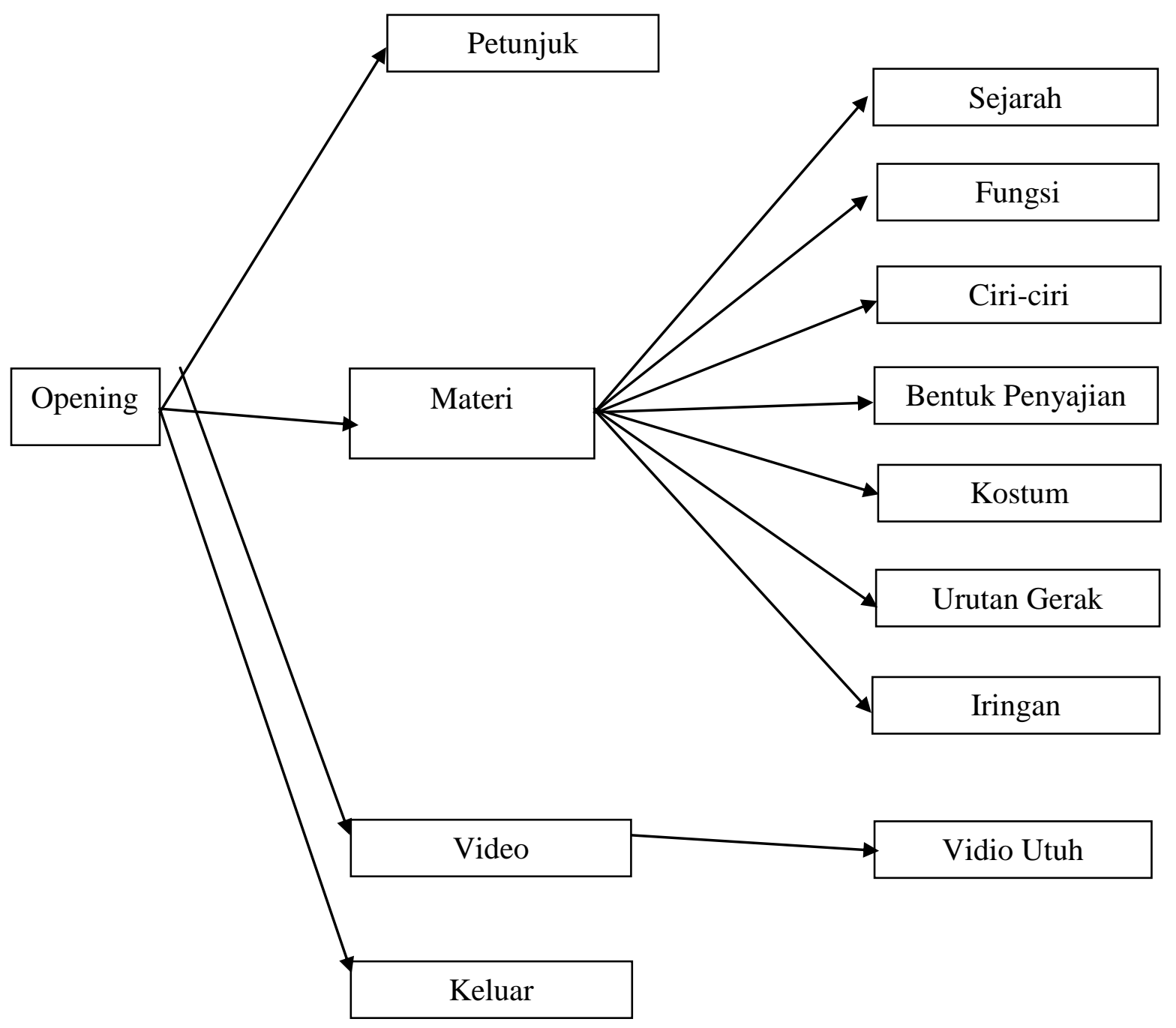

Gambar 1. Flow chartmedia pembelajaran Tari Gambyong Pareanom

\section{Pengembangan produk awal}

Pengembangan produk awal ini berupa pengambilan adegan seluruh adegan audio visual baik display kostum, display rias, tarian secara utuh, dan 
tarian ragam per ragam. Adapun skenario produk awal dapat ditampilkan dengan bentuk Story Board.

\begin{tabular}{|c|c|c|c|}
\hline SOUND \\
\hline Gendhing \\
iringan \\
Gambyong
\end{tabular}




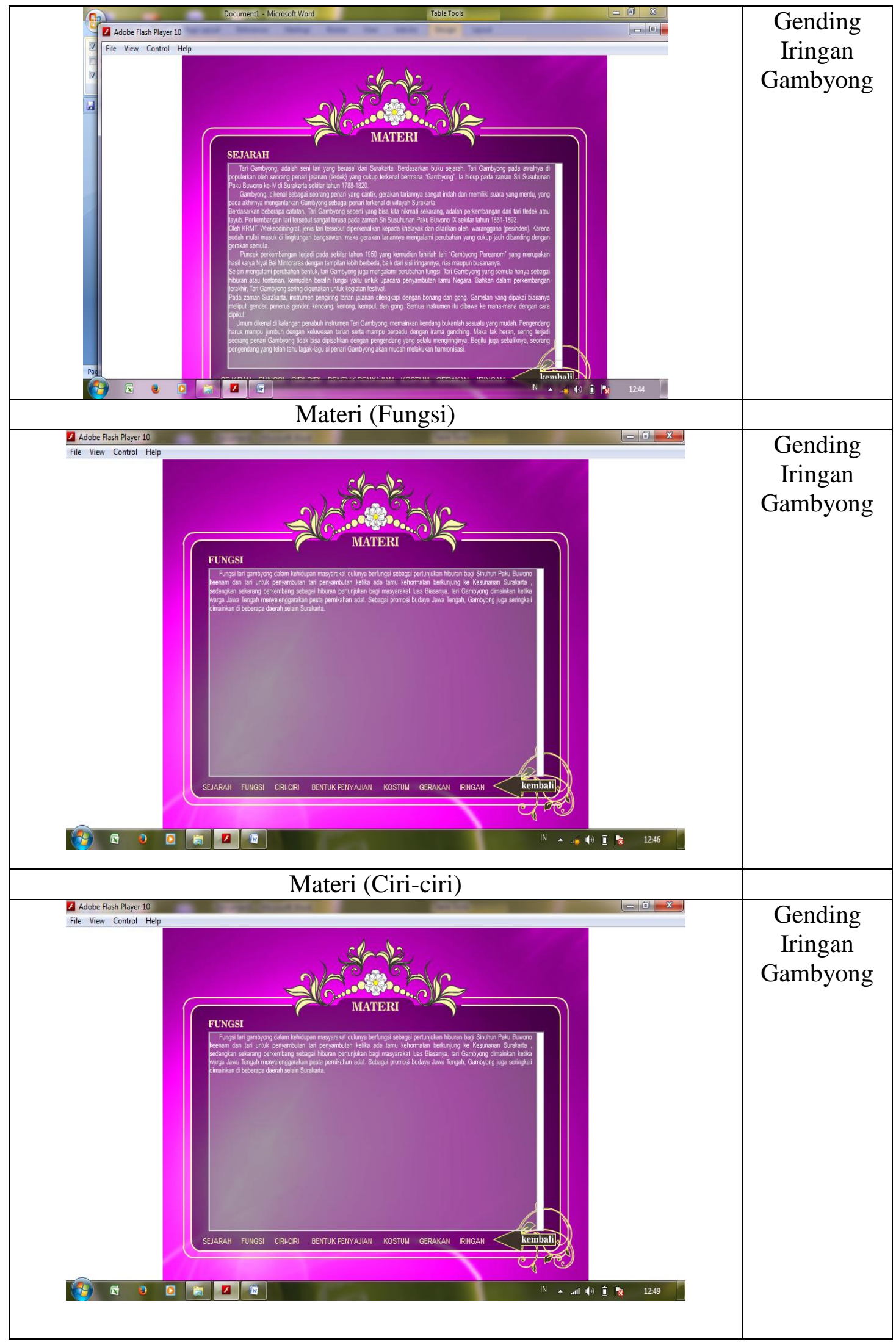




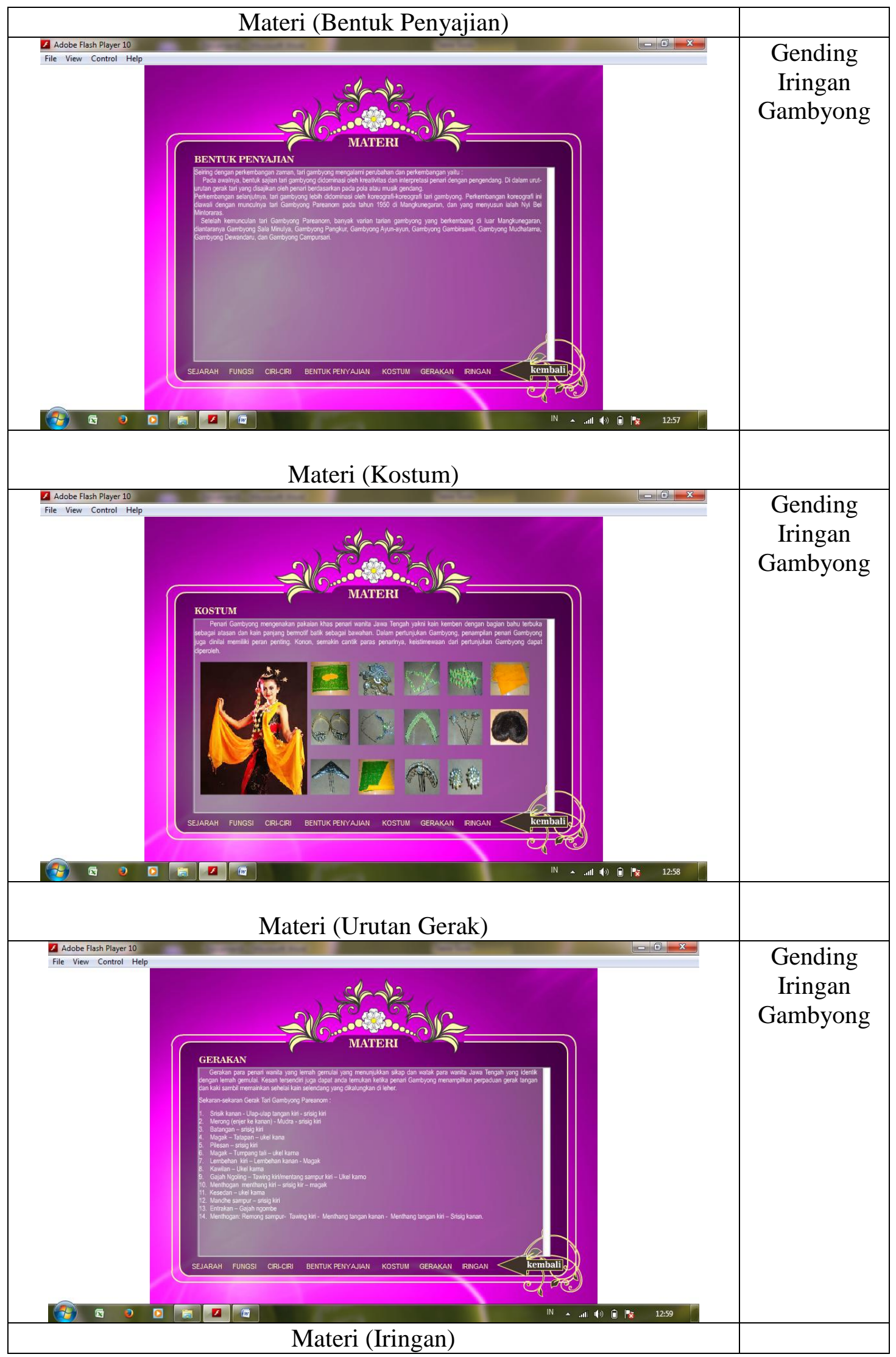




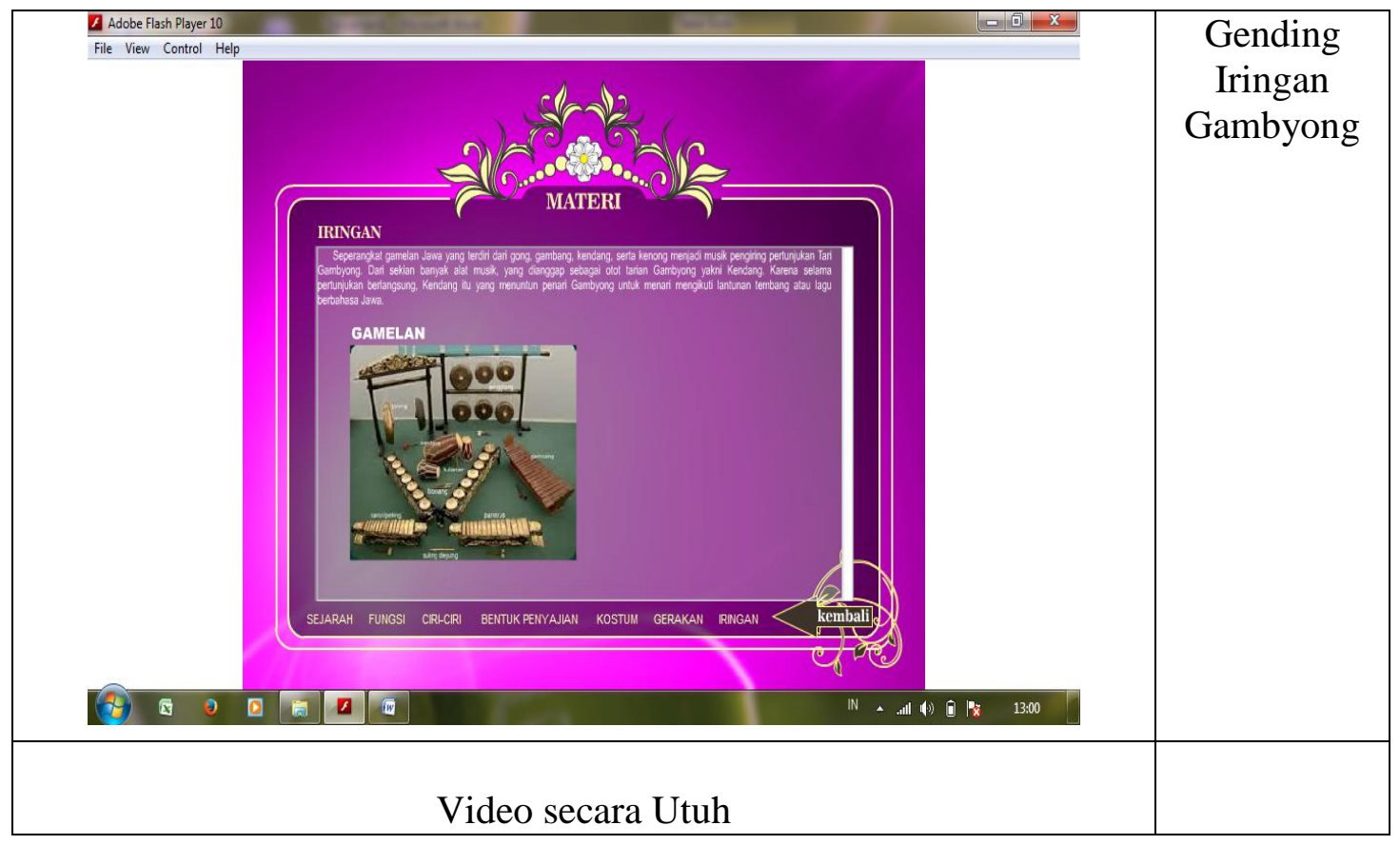

\section{Uji Validasi Ahli}

Uji validasi ahli dilakukan oleh ahli bidang studi. Ahli bidang studi (materi) yang dimintai masukannya adalah Dra. Yuli Sectiorini, M.Hum. dosen tari Surakartadi Jurusan Pendidikan Seni Tari Fakultas Bahasa dan Seni Universitas Negeri Yogyakarta.Ahli media pembelajaran seni yang dimintai masukan adalah Drs. Marwanto, M.Hum. dosen Pendidikan Seni Tari Fakultas Bahasa dan Seni Universitas Negeri Yogyakarta.

Tabel 1

Data hasil validasi ahli

\begin{tabular}{|c|c|c|c|c|c|c|c|c|c|}
\hline \multirow{2}{*}{ Responden } & \multicolumn{7}{|c|}{ Nomor Item } & \multirow{2}{*}{ Jumlah } \\
\cline { 2 - 12 } & 1 & 2 & 3 & 4 & 5 & 6 & 7 & 8 & \\
\hline Yuli Sectiorini & 4 & 4 & 3 & 4 & 5 & 5 & 4 & 4 & 33 \\
\hline Marwanto & 4 & 3 & 4 & 3 & 4 & 5 & 5 & 3 & 31 \\
\hline Jumlah & 8 & 7 & 7 & 7 & 9 & 10 & 9 & 7 & 64 \\
\hline Rata-rata & 4 & 3.5 & 3.5 & 3.5 & 4.5 & 5 & 4.5 & 3.5 & 4 \\
\hline
\end{tabular}


Berdasarkan penilaian dari dua orang ahli materi dan media, diperoleh skor rata-rata 4 . Beberapa aspek yang dipandang masih lemah adalah item nomor $2,3,4$, dan 8 yang mendapat penilaian 3,5.

\section{Uji Coba Kelompok Kecil}

Uji coba kelompok kecil ini dilakukan terhadap 4 orang mahasiswa program studi Pendidikan Seni tari semester III, yang mengambil mata kuliah Tari Surakarta I. Mahasiswa dipilih yang kemampuannya hiterogen.

Tabel 2

Data Uji Coba terbatas

\begin{tabular}{|c|c|c|c|c|c|c|c|c|c|}
\hline \multirow[t]{2}{*}{ Responden } & \multicolumn{8}{|c|}{ Item } & \multirow[t]{2}{*}{ Jumlah } \\
\hline & 1 & 2 & 3 & 4 & 5 & 6 & 7 & 8 & \\
\hline 1 & 4 & 4 & 4 & 5 & 5 & 5 & 4 & 4 & 35 \\
\hline 2 & 4 & 3 & 3 & 5 & 5 & 5 & 5 & 5 & 35 \\
\hline 3 & 4 & 4 & 4 & 5 & 5 & 5 & 5 & 5 & 37 \\
\hline 4 & 4 & 3 & 3 & 5 & 5 & 4 & 4 & 4 & 32 \\
\hline Jumlah & 16 & 14 & 14 & 20 & 20 & 19 & 18 & 18 & 139 \\
\hline Rata-rata & 4 & 3.5 & 3.5 & 5 & 5 & 4.75 & 4.5 & 4.5 & 4.34 \\
\hline
\end{tabular}

Berdasarkan masukan dari mahasiswa skor media termasuk kategori baik yaitu rata-rata 4,34 sedangkan yang masih kelihatan lemah adalah pada aspek 2 dan 3 yaitu aspek gambar dan suara yang ditampilkan. Untuk mengetahui skor gabungan dari ahli dan mahasiswa dapat dilihat pada tabel berikut:

\section{Tabel 3}

Skor kualitas Media Tari Gambyong Pareanom

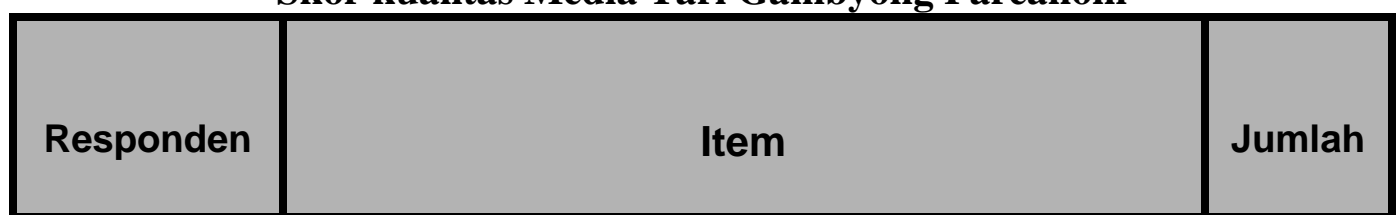




\begin{tabular}{|c|c|c|c|c|c|c|c|c|c|}
\hline & 1 & 2 & 3 & 4 & 5 & 6 & 7 & 8 & \\
\hline Ahli & 4 & 3.5 & 3.5 & 3.5 & 4.5 & 5 & 4.5 & 3.5 & 4 \\
\hline Mahasiswa & 4 & 3.5 & 3.5 & 5 & 5 & 4.75 & 4.5 & 4.5 & 4.34 \\
\hline Rata-rata & 4 & 3.5 & 3.5 & 4.25 & 4.75 & 4.87 & 4.5 & 4 & 4.17 \\
\hline
\end{tabular}

\section{Revisi}

Berdasarkan masukan-masukan,maka perbaikan difokuskan pada editing gambar dengan penambahan-penambahan pada aspek yang dianggap kurang.

\section{Uji coba Kelompok Besar}

Uji coba kelompok besar adalah mahasiswa jurusan Pendidikan Seni Tari fakultas Bahasa dan Seni Universitas Negeri Yogyakarta yang melaksanakan kuliah Tari Surakarta I. Uji coba kelompok besar ini dilakukan terhadap 20 mahasiswa yang mengambil mata kuliah Tari Surakarta I pada semester gasal tahun 2013.

Tabel 4

Skor Fungsi Media dalam Pembelajaran

\begin{tabular}{|c|c|c|c|c|c|c|c|c|c|}
\hline \multirow{2}{*}{ Responden } & \multicolumn{7}{|c|}{ Item } & Jumlah \\
\cline { 2 - 11 } & 1 & 2 & 3 & 4 & 5 & 6 & 7 & 8 & \\
\hline 1 & 3 & 3 & 3 & 4 & 4 & 3 & 4 & 3 & 30 \\
\hline 2 & 3 & 3 & 4 & 4 & 3 & 4 & 4 & 3 & 28 \\
\hline 3 & 3 & 4 & 3 & 4 & 3 & 4 & 3 & 4 & 28 \\
\hline 4 & 3 & 3 & 3 & 4 & 4 & 3 & 4 & 3 & 27 \\
\hline 5 & 3 & 3 & 3 & 3 & 3 & 3 & 3 & 3 & 18 \\
\hline 6 & 3 & 3 & 4 & 5 & 5 & 5 & 5 & 5 & 35 \\
\hline 7 & 4 & 4 & 4 & 5 & 5 & 5 & 5 & 5 & 37 \\
\hline 8 & 4 & 4 & 5 & 5 & 5 & 4 & 4 & 4 & 35 \\
\hline 9 & 5 & 5 & 5 & 5 & 5 & 5 & 5 & 5 & 40 \\
\hline 10 & 2 & 4 & 5 & 4 & 4 & 4 & 4 & 5 & 32 \\
\hline
\end{tabular}




\begin{tabular}{|c|c|c|c|c|c|c|c|c|c|}
\hline 11 & 4 & 4 & 4 & 5 & 5 & 5 & 5 & 5 & 37 \\
\hline 12 & 2 & 3 & 2 & 2 & 3 & 4 & 4 & 3 & 23 \\
\hline 13 & 4 & 5 & 5 & 5 & 3 & 3 & 2 & 2 & 29 \\
\hline 14 & 4 & 4 & 4 & 5 & 5 & 5 & 5 & 5 & 37 \\
\hline 15 & 4 & 4 & 4 & 5 & 5 & 5 & 5 & 5 & 37 \\
\hline 16 & 4 & 3 & 3 & 5 & 5 & 5 & 5 & 5 & 35 \\
\hline 17 & 4 & 4 & 4 & 5 & 5 & 5 & 4 & 4 & 35 \\
\hline 18 & 4 & 3 & 3 & 5 & 5 & 4 & 4 & 4 & 32 \\
\hline 19 & 4 & 4 & 4 & 4 & 4 & 5 & 5 & 4 & 34 \\
\hline 20 & 4 & 3 & 4 & 3 & 4 & 5 & 5 & 3 & 31 \\
\hline jumlah & 81 & 73 & 76 & 87 & 85 & 96 & 85 & 80 & 640 \\
\hline Rata-rata & 4.05 & 3.65 & 3.8 & 4.35 & 4.25 & 4.8 & 4.25 & 4 & 4.14 \\
\hline
\end{tabular}

Berdasarkan skor tersebut di atas, bahwa pada tari Gambyong Pareanom memiliki skor rata-rata 4.14. Sedangkan aspek yang masih lemah adalah aspek kedua yaitu pada kualitas gambar yang ditampilkan yaitu hanya mendapat skor 3.65 .

\section{Evaluasi Akhir}

Berdasarkan respon dari lapangan dapat disimpulkan bahwa media pembelajaran ini dapat meningkatkan motivasi dan pemahaman tentang teknik gerak, irama, dan ekspresi/penjiwaan.

\section{E. PENUTUP}

Kesimpulan yang diperoleh dari penelitian pengembangan ini adalah bahwa persepsi mahasiswa tentang kemampuan media pembelajaran Tari Gambyong Pareanom adalah sebagai berikut:

Perolehan skor persepsi mahasiswa tentang kemampuan media dalam meningkatkan motivasi belajar adalah: 4,25; pemahaman teknik gerak 4,8; pemahaman irama 4, 25; pemahaman ekspresi dan penjiwaan 4. Sedangkan dari 
segi teknis, persepsi mahasiswa tentang kualitas peraga yang dipergunakan adalah 4,05; kualitas gambar 3,65; kualitas suara 3,8; dan kebermaknaan materi 4,35. Rata-rata skor keseluruhan adalah 4,14. Berdasarkan perolehan skor maka dapat disimpulkan bahwa persepsi mahasiswa tentang kemampuan dan kualitas media video tari Gambyong Pareanom secara keseluruhan adalah baik.

\section{DAFTAR PUSTAKA}

Arsyad, Azhar. 2009. Media Pembelajaran. Jakarta: PT Raja Grafindo Persada

Lewis Gina dan Hollingsworth Pat. 2008. Pembelajaran Aktif (terjemahan). Jakarta: PT Macanan Jaya Cemerlang

Munandar, Utami. 1999. Pengembangan Kreativitas Anak Berbakat

Muslich, Masnur. 2009. Pembelajaran Berbasis Kompetensi dan Kontekstual. Jakarta: Bumi Aksara

Sardiman A.M. 2007. Interaksi dan Motivasi Belajar Mengajar. Jakarta: PT Raja Grafindo Persada

Soenarto. 2010. "Penelitian Pengembangan (Research \& Development) sebagai upaya peningkatan Kualitas Pembelajaran", makalah seminar. Yogyakarta: PHK-I UNY 2010

Sugiyono. 2013. Metode Penelitian Kuantitatif Kualitatif dan $R \& D$. Bandung: Alfabeta

Wiriaatmadja, Rochiati. 2006. Metode Penelitian Tindakan Kelas. Bandung: PT Remaja Rosdakarya. 